\title{
Design, synthesis, and biological profile of novel $N$-(5-aryl-1,3,4-thiadiazol-2-yl) hydrazinecarboxamides
}

\author{
Mohammed Farrag El-Behairy a, Mohamed Nabil Aboul-Enein a,*, Aida Abdel-Sattar El-Azzouny a, \\ Ola Ahmed Saleh a, Yousreya Aly Maklad a, Mona Elsayed Aboutabl a and Amany Sayed Maghraby b \\ a Medicinal and Pharmaceutical Chemistry Department, Pharmaceutical and Drug Industries Research Division, National Research Centre, Dokki, 12311, Cairo, \\ Egypt \\ b Therapeutic Chemistry Department, Pharmaceutical and Drug Industries Research Division, Immunology and Infectious Diseases Laboratory, Centre of Excellence \\ for Advanced Sciences, National Research Centre, Dokki, 12311, Cairo, Egypt \\ *Corresponding author at: Medicinal and Pharmaceutical Chemistry Department, Pharmaceutical and Drug Industries Research Division, National Research Centre, \\ Dokki, 12311, Cairo, Egypt. \\ Tel.: +20.2.33335454. Fax: +20.2.33370931. E-mail address: mnaboulenein@yahoo.com (M.N. Aboul-Enein).
}

\section{ARTICLE INFORMATION}

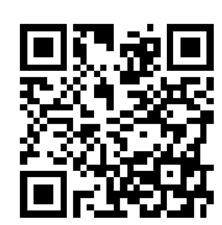

DOI: $10.5155 /$ eurjchem.5.3.488-496.1073

Received: 10 April 2014

Received in revised form: 29 April 2014

Accepted: 29 April 2014

Online: 30 September 2014

\section{KEYWORDS}

\section{ELISA}

Thiadiazoles

Arylthiadiazole

Anticonvulsants

Immunomodulatory

Hydrazinecarboxamides

\section{Introduction}

Disorders of immune system, autoimmunity or immunedeficiency, lead to many devastating diseases. The immune system can be manipulated specifically by vaccination or nonspecifically by immunomodulation, which includes both immunostimulatory and immunosuppressive agents [1]. Immunostimulatory agents capable of enhancing host defense mechanisms to provide protection against infections and to overcome immunodeficiency cases. Immunosuppressant agents, which manage autoimmunity, are widely used in transplantation, inflammation, and many allergic manifestations [2]. Noteworthy, many immune diseases like HIV and rheumatoid arthritis are still looking for better control.

Heterocyclic compounds enclosing five-membered rings gained importance due to their adaptable biological properties. Among these moieties, thiadiazoles exhibited a wide variety of biological activities like antimicrobial [3], anti-inflammatory [4], anticancer [5], anticonvulsant [6], antioxidant, radioprotective [7], and anti-leishmanial [8]. They are represented in pharmaceutical market via several drugs like carbonic anhydrase inhibitors (e.g. acetazolamide and methazolamide), also in the third and fourth generation cephalosporins (e.g. Cefazolin and Cefazedon) (Figure 1). Thiadiazole is a constrained pharmacophore with hydrogen binding domain and electron donor system. it is occurring in nature in four isomeric forms (1,2,3-thiadiazole, 1,2,5-thiadiazole, 1,2,4-thiadiazole and 1,3,4-thiadiazole) where 1,3,4-thiadiazole isomer is the most investigated one [9].

Despite the plethora of activities that have been correlated to thiadiazole derivatives, immune related responses still at very primitive stage or by other words it is the least explored activity. The most important immune active thiadiazole derivative is YM-58483 (Figure 2). It is commercially available and used mainly in research work as immunosuppressant. Many mechanisms were suggested for the biological effect of YM-58483 like inhibiting both $\mathrm{Ca}^{2+}$ influx and interleukin-2 (IL2) production in lymphocytes [10]. In addition, it inhibits $T$ helper type 2 (Th2) cytokine production [11]. Other thiadiazole-carboxamide derivatives have been reported with immunomodulatory activity like compounds I [12] and II [13] (Figure 2) where 1,3,4-thiadiazole was connected to hydro- 

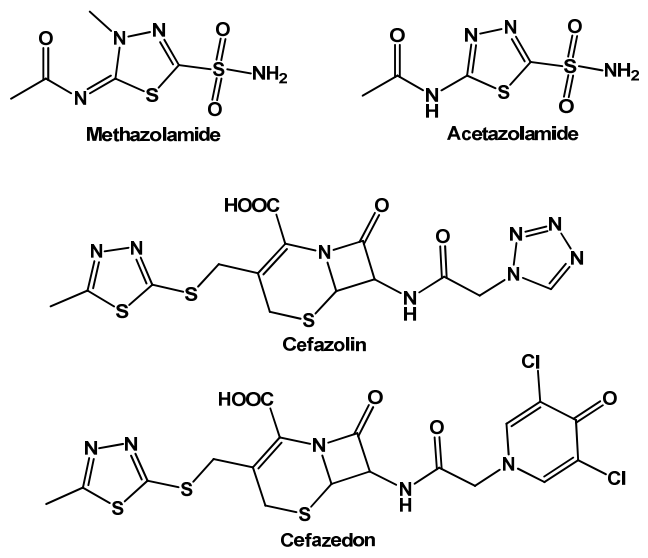

Figure 1. Market available 1,3,4-thiadiazole containing drugs.
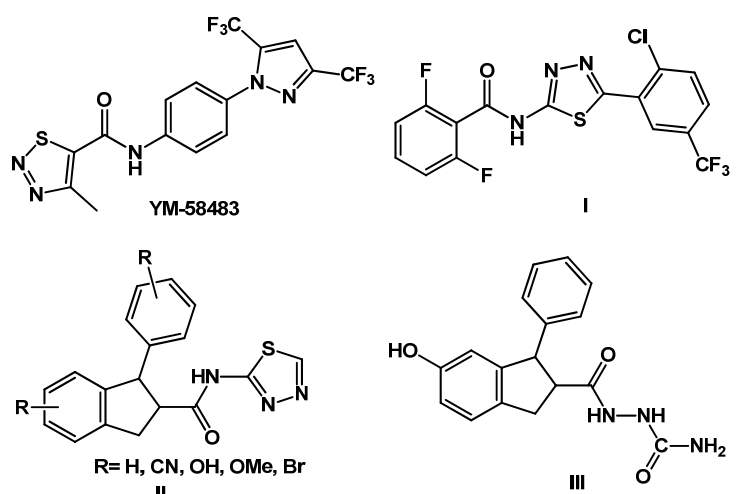

Figure 2. Immunomodulatory thiadiazole and hydrazinecarboxamide derivatives.

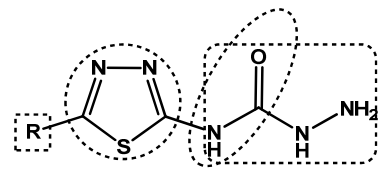

Figure 3. The joint pharmacophoric model.

phobic domain via carboxamide moiety. Noteworthy, hydrazinecarboxamide derivatives are also still uncharted as immunomodulatory agents despite their other effective biological profiles [14]. Compound III (Figure 2) is one of the very rare instances of immunomodulatory hydrazinecarboxamide derivatives [13].

In the present work, we were motivated to discover more about thiadiazoles and hydrazinecarboxamides as immunemodulatory agents. However, the shortage of reported data relating thiadiazoles and hydrazinecarboxamides to immune response pushed us to design very simple candidates which could, in the future, act as prototypic model and subjected for further modifications to improve the activity. Thus, joint model of immune active pharmacophoric moieties has been designed (Figure 3). The pharmacophoric model contains thiadiazole, hydrazinecarboxamide, carboxamide (as a part of hydrazine carboxamide scaffold) and hydrophobic domain (R). Then very concise series, enough to act as a scratch, has been synthesized and pharmacologically evaluated as immunomodulators. In addition, the well-documented anticonvulsant activity of thiadiazoles and hydrazinecarboxamides has been studied for the novel candidates.

\section{Experimental}

\subsection{Materials}

\subsubsection{Animals}

Swiss albino mice weighing 18-25 gram were used for evaluation of the anticonvulsant, neurotoxicity, humoral and cellular immune responses, as well as histopathological examination of the liver. The animals used in this study were purchased from Animals House Colony of the National Research Centre, Cairo, Egypt. Animals were housed under standardized conditions (room temperature $23 \pm 2{ }^{\circ} \mathrm{C}$; relative humidity $55 \pm 5 \% ; 12 \mathrm{~h}$ light/dark cycle) and had free access to tap water and standard mice chow throughout the whole experimental period. Anesthetic procedures complied with ethical guidelines approved by the Ethical Committee of the Federal Legislation and National Institutes of Health Guidelines in USA and were approved by the Medical Ethical Committee of the National Research Centre in Egypt. 


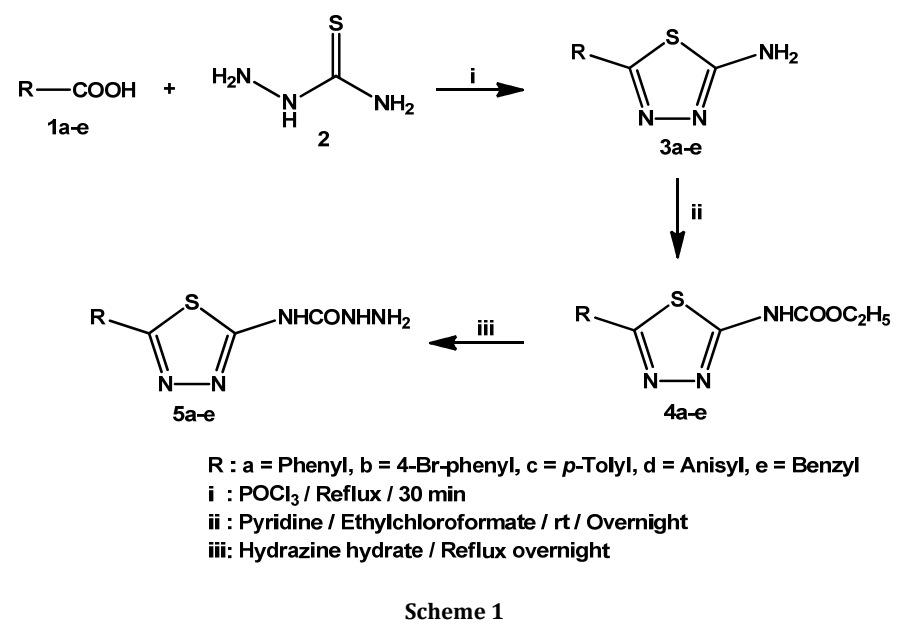

\subsubsection{Chemicals and drugs}

Pentylenetetrazole (PTZ), tween-20 and o-phenylene diamine (OPD) were purchased from Sigma (St. Louis, Mo, USA), fetal calf serum (FCS) was purchased from Biochrome KG; (Berlin, Germany), Goat-anti mouse IgM conjugated with horseradish peroxidase and Goat-anti mouse IgG conjugated with horseradish peroxidase were purchased from KPL (Gaithersburg, MD, USA). All melting points were determined using Electrothermal Capillary melting point apparatus and are uncorrected. Infrared (IR) spectra were recorded as thin film (for oils) in $\mathrm{NaCl}$ discs or as $\mathrm{KBr}$ pellets (for solids) with JASCO FT/IR-6100 Spectrometer and values are represented in $\mathrm{cm}^{-1}$. Mass spectral data were obtained with electron impact (EI) ionization technique at $70 \mathrm{eV}$ from a Finnigan Mat SSQ-7000 Spectrophotometer. ${ }^{1} \mathrm{H}$ NMR (300 or $500 \mathrm{MHz}$ ) and ${ }^{13} \mathrm{C}$ NMR $(125 \mathrm{MHz})$ spectra were carried out on Jeol ECA $500 \mathrm{MHz}$ spectrometer and Bruker $300 \mathrm{MHz}$ using TMS as internal standard and chemical shift values were recorded in ppm on $\delta$ scale. The ${ }^{1} \mathrm{H}$ NMR data were represented as follows: chemical shifts, multiplicity (s. singlet, d. doublet, t. triplet and $\mathrm{m}$. multiplet), number of protons, and type of protons. The ${ }^{13} \mathrm{C}$ NMR data were represented as chemical shifts and type of carbons. Silica gel TLC (thin layer chromatography) cards from Merck (silica gel precoated aluminum cards with fluorescent indicator at $245 \mathrm{~nm}$ ) were used for thin layer chromatography. Visualization was performed by illumination with UV light source $(254 \mathrm{~nm})$.

\subsection{Methods}

\subsubsection{Chemistry}

\subsubsection{Synthesis of 5-aryl-1,3,4-thiadiazol-2-amines (3a-e)}

A mixture of substituted benzoic acid (1a-e) $(0.033 \mathrm{~mol})$, thiosemicarbazide (2) $(0.033 \mathrm{~mol}, 3.0 \mathrm{~g})$ and phosphorusoxy chloride $\left(\mathrm{POCl}_{3}\right)(10 \mathrm{~mL})$ was refluxed gently for $30 \mathrm{~min}$. The heating was stopped and water $(100 \mathrm{~mL})$ was added very slowly till complete decomposition of $\mathrm{POCl}_{3}$ then the mixture was rendered alkaline under cooling using $50 \% \mathrm{KOH}$ solution. The formed precipitate was filtered, washed with water, and dried to afford the corresponding 1,3,4-thiadiazol-2-amines (3a-e) (Scheme 1).

5-Phenyl-1,3,4-thiadiazol-2-amine (3a): Yield: 61\%. M.p.: $260{ }^{\circ} \mathrm{C}$ (Lit. 225-226 ${ }^{\circ} \mathrm{C}$ ) [15].

5-(4-Bromophenyl)-1,3,4-thiadiazol-2-amine (3b): Yield: 47\%. M.p.: $210-212^{\circ} \mathrm{C}$ (Lit. $222-224^{\circ} \mathrm{C}$ ) [16]
5-p-Tolyl-1,3,4-thiadiazol-2-amine (3c): Yield: 61\%. M.p.: $216^{\circ} \mathrm{C}$ (Lit. $214-216^{\circ} \mathrm{C}$ ) [15].

5-(4-Methoxyphenyl)-1,3,4-thiadiazol-2-amine (3d): Yield: 61\%. M.p.: $186^{\circ} \mathrm{C}$ (Lit. $187-189^{\circ} \mathrm{C}$ ) [17].

5-Benzyl-1,3,4-thiadiazol-2-amine (3e): Yield: 42\%. M.p.: $206^{\circ} \mathrm{C}$ (Lit. $205-210^{\circ} \mathrm{C}$ ) [18].

\subsubsection{Synthesis of ethyl 5-aryl-1,3,4-thiadiazol-2-yl carbamates (4a-e)}

Thiadiazole derivatives 3a-e $(0.02 \mathrm{~mol})$ was dissolved in pyridine $20 \mathrm{~mL}$ followed by addition of ethylchloroformate $(0.022 \mathrm{~mol}, 2.13 \mathrm{~g}, 2.0 \mathrm{~mL})$. The mixture stirred at room temperature overnight then poured on ice-cold aqueous $\mathrm{HCl}$ (200 mL 20\%). The precipitate was filtered washed with water, and dried to afford the corresponding carbamates 4a-e (Scheme 1).

Ethyl 5-phenyl-1,3,4-thiadiazol-2-ylcarbamate (4a): Yield: 53\%. M.p.: 206-208 ${ }^{\circ} \mathrm{C}$ (Lit. 198-200 ${ }^{\circ} \mathrm{C}$ ) [19].

Ethyl 5-(4-bromophenyl)-1,3,4-thiadiazol-2-ylcarbamate (4b): Yield: 68\%. M.p.: Decomposition. ${ }^{1} \mathrm{H}$ NMR $(300 \mathrm{MHz}$, $\left.\mathrm{CDCl}_{3}, \delta, \mathrm{ppm}\right): 0.8\left(\mathrm{~m}, 3 \mathrm{H}, \mathrm{CH}_{2} \mathrm{CH}_{3}\right), 3.8\left(\mathrm{~m}, 2 \mathrm{H}, \mathrm{CH}_{2} \mathrm{CH}_{3}\right), 7.2-$ $7.4(\mathrm{~m}, 4 \mathrm{H}, \mathrm{Ar}-\mathrm{H})$.

Ethyl 5-p-tolyl-1,3,4-thiadiazol-2-ylcarbamate (4c): Yield: 88\%. M.p.: $280{ }^{\circ} \mathrm{C} .{ }^{1} \mathrm{H}$ NMR $\left(300 \mathrm{MHz}, \mathrm{CDCl}_{3}, \delta, \mathrm{ppm}\right): 0.9$ (t, $3 \mathrm{H}$, $\left.J=6.9 \mathrm{~Hz}, \mathrm{CH}_{2} \mathrm{CH}_{3}\right), 2.4\left(\mathrm{~s}, 3 \mathrm{H} \mathrm{CH} \mathrm{H}_{3}\right), 4.4(\mathrm{q}, 2 \mathrm{H}, J=6.85 \mathrm{~Hz}$, $\mathrm{CH}_{2} \mathrm{CH}_{3}$ ), $7.2(\mathrm{~d}, 2 \mathrm{H}, J=8.5 \mathrm{~Hz}, \mathrm{Ar}-\mathrm{H}), 7.8(\mathrm{~d}, 2 \mathrm{H}, J=7.6 \mathrm{~Hz}, \mathrm{Ar}-$ $\mathrm{H})$.

Ethyl 5-(4-methoxyphenyl)-1,3,4-thiadiazol-2-ylcarbamate (4d): Yield: $86 \%$. M.p.: $206{ }^{\circ} \mathrm{C} .{ }^{1} \mathrm{H}$ NMR $\left(300 \mathrm{MHz}, \mathrm{CDCl}_{3}, \delta\right.$ ppm): 0.9 (t, $\left.3 \mathrm{H}, J=6.85 \mathrm{~Hz}, \mathrm{CH}_{2} \mathrm{CH}_{3}\right), 3.8\left(\mathrm{~s}, 3 \mathrm{H} \mathrm{OCH} \mathrm{OCH}_{3}\right), 4.4$ (q, $\left.2 \mathrm{H}, J=6.9 \mathrm{~Hz}, \mathrm{CH}_{2} \mathrm{CH}_{3}\right), 7.0(\mathrm{~d}, 2 \mathrm{H}, J=8.4 \mathrm{~Hz}, \mathrm{Ar}-\mathrm{H}), 7.8(\mathrm{~d}, 2 \mathrm{H}, J$ $=7.6 \mathrm{~Hz}, \mathrm{Ar}-\mathrm{H})$.

Ethyl 5-benzyl-1,3,4-thiadiazol-2-ylcarbamate (4e): Yield: 36\%. M.p.: $132-134{ }^{\circ} \mathrm{C}$ (Lit. $138-140{ }^{\circ} \mathrm{C}$ ) [19].

\subsubsection{Synthesis of $\mathrm{N}$-(5-aryl-1,3,4-thiadiazol-2-yl) hydrazinecarboxamides (5a-e)}

A mixture of the appropriate carbamate $4 a-e(1 \mathrm{~g})$ and hydrazine hydrate $(10 \mathrm{~mL})$ was stirred under reflux for $18 \mathrm{hr}$ (TLC controlled). After completion of the reaction, the mixture was cooled and filtered to afford the corresponding thiadiazole2-hydrazinecarboxamides (5a-e) (Scheme 1).

$N$-(5-Phenyl-1,3,4-thiadiazol-2-yl)hydrazinecarboxamide (5a): Yield: 50\%. M.p.: $240{ }^{\circ} \mathrm{C}$. FT-IR (KBr, $\left.v, \mathrm{~cm}^{-1}\right): 3277\left(\mathrm{NH}_{2}\right)$, $3083(\mathrm{NH}), 1633(\mathrm{C}=0), 1515(\mathrm{C}=\mathrm{N}) .{ }^{1} \mathrm{H}$ NMR $(500 \mathrm{MHz}$, DMSO$d_{6} /$ Methanol- $\left.d_{4}, \delta, \mathrm{ppm}\right)$ : 7.3-7.7 (m, 5H, Ar-H), $7.72(\mathrm{~s}, 2 \mathrm{H}, \mathrm{NH})$ 
${ }^{13} \mathrm{C}$ NMR (125 MHz, DMSO- $\left.d_{6}, \delta, \mathrm{ppm}\right): 126(\mathrm{CH}), 129(\mathrm{CH}), 130$ (CH), $131(\mathrm{C}), 156(\mathrm{C}=0), 169(\mathrm{C}=\mathrm{N})$. MS $(\mathrm{m} / \mathrm{z}): 236.00[\mathrm{M}+\mathrm{H}]^{+}$. $N$-(5-(4-Bromophenyl)-1,3,4-thiadiazol-2-yl)hydrazine carboxamide (5b): Yield: $38 \%$. M.p.: $202^{\circ} \mathrm{C}$. FT-IR $\left(\mathrm{KBr}, v, \mathrm{~cm}^{-1}\right)$ : 3277 (NH2), $3074(\mathrm{NH}), 1637$ (C=0), $1511(\mathrm{C}=\mathrm{N}) .{ }^{1} \mathrm{H}$ NMR (500 MHz, DMSO- $d_{6} /$ Methanol- $\left.d_{4}, \delta, \mathrm{ppm}\right):$ 7.5-7.7 (m, $\left.4 \mathrm{H}, \mathrm{Ar}-\mathrm{H}\right) .{ }^{13} \mathrm{C}$ NMR (125 MHz, DMSO- $\left.d_{6}, \delta, \mathrm{ppm}\right): 123(\mathrm{CH}), 128(\mathrm{CH}), 130$ (CH), $132(\mathrm{C}), 157(\mathrm{C}=0), 169(\mathrm{C}=\mathrm{N})$. MS (m/z): $314.00[\mathrm{M}+\mathrm{H}]^{+}$ $N$-(5-(4-Methylphenyl)-1,3,4-thiadiazol-2-yl)hydrazine carboxamide (5c): Yield: $27 \%$. M.p.: $160^{\circ} \mathrm{C}$. FT-IR $\left(\mathrm{KBr}, v, \mathrm{~cm}^{-1}\right)$ : $3285(\mathrm{NH} 2), 3085(\mathrm{NH}), 1636(\mathrm{C}=0), 1513(\mathrm{C}=\mathrm{N}) .{ }^{1} \mathrm{H}$ NMR $(500$ MHz, DMSO- $d_{6} /$ Methanol- $\left.d_{4}, \delta, \mathrm{ppm}\right): 2.3\left(\mathrm{~s}, 3 \mathrm{H}, \mathrm{CH}_{3}\right), 7.2-7.6$ (m, 4H, Ar-H). ${ }^{13} \mathrm{C}$ NMR (125 MHz, DMSO- $\left.d_{6}, \delta, \mathrm{ppm}\right): 21.4$ $\left(\mathrm{CH}_{3}\right), 126.7(\mathrm{CH}), 128.8(\mathrm{CH}), 130(\mathrm{CH}), 139(\mathrm{C}), 157(\mathrm{C}=0)$, $168(\mathrm{C}=\mathrm{N})$. MS $(\mathrm{m} / \mathrm{z}): 248.00[\mathrm{M}-\mathrm{H}]^{+}$.

$N$-(5-(4-Methoxyphenyl)-1,3,4-thiadiazol-2-yl)hydrazine carboxamide (5d): Yield: 37\%. M.p.: 198-200 ${ }^{\circ} \mathrm{C}$. FT-IR $(\mathrm{KBr}, v$, $\left.\mathrm{cm}^{-1}\right)$ : $3273(\mathrm{NH} 2), 3098(\mathrm{NH}), 1608(\mathrm{C}=0), 1514(\mathrm{C}=\mathrm{N}) .{ }^{1} \mathrm{H}$ NMR $\left(500 \mathrm{MHz}, \mathrm{DMSO}-d_{6} /\right.$ Methanol- $\left.d_{4}, \delta, \mathrm{ppm}\right): 3.8(\mathrm{~s}, 3 \mathrm{H}$, $\left.\mathrm{CH}_{3}\right), 7.0-7.7(\mathrm{~m}, 4 \mathrm{H}, \mathrm{Ar}-\mathrm{H}) .{ }^{13} \mathrm{C}$ NMR (125 MHz, DMSO- $d_{6}, \delta$, ppm): $55.8\left(\mathrm{CH}_{3}\right), 115(\mathrm{CH}), 124(\mathrm{CH}), 128(\mathrm{CH}), 156(\mathrm{C}), 160$ $(\mathrm{C}=0), 168(\mathrm{C}=\mathrm{N})$. MS $(\mathrm{m} / \mathrm{z}): 265.00[\mathrm{M}]^{+}$.

$N$-(5-Benzyl-1,3,4-thiadiazol-2-yl)hydrazinecarboxamide (5e): Yield: $43 \%$. M.p.: 204-206 ${ }^{\circ} \mathrm{C}$. FT-IR (KBr, v, $\left.\mathrm{cm}^{-1}\right): 3444$ (NH2), $3163(\mathrm{NH}), 1728(\mathrm{C}=0), 1564(\mathrm{C}=\mathrm{N}) .{ }^{1} \mathrm{H}$ NMR (500 MHz, DMSO- $d_{6} /$ Methanol- $\left.d_{4}, \delta, \mathrm{ppm}\right): 4.2\left(\mathrm{~s}, 2 \mathrm{H}, \mathrm{CH}_{2}\right), 7.0-7.2(\mathrm{~m}, 5 \mathrm{H}$, Ar-H). ${ }^{13}$ C NMR (125 MHz, DMSO-d $\left.d_{6}, \delta, \mathrm{ppm}\right): 39.7\left(\mathrm{CH}_{2}\right), 127$ (CH), $129(\mathrm{CH}), 138(\mathrm{CH}), 138.5(\mathrm{C}), 158(\mathrm{C}=0), 169(\mathrm{C}=\mathrm{N})$. MS $(\mathrm{m} / \mathrm{z}): 249.10[\mathrm{M}]^{+}$.

\subsubsection{Biology}

\subsubsection{Anticonvulsant screening tests}

\subsection{Subcutaneous pentylenetetrazole test}

To determine the production of threshold or minimal (clonic) seizures, scPTZ test was performed, where an aqueous solution of PTZ at a dose of $85 \mathrm{mg} / \mathrm{kg}$ [20] was administered subcutaneously in a loose fold of skin on the back of the mice neck. Six mice were used in both the control and the experimental groups. The test is carried out by injecting PTZ subcutaneously 30 minutes after i.p. injection of the test compounds at dose level of $100 \mathrm{mg} / \mathrm{kg}$. The animals were observed for the following 30 minutes for the occurrence of seizures. A threshold convulsion was defined as one episode of clonic convulsions which persist for at least a $5 \mathrm{~s}$ period. Absence of a single $5 \mathrm{~s}$ episode of clonic spasms during the period of observation is taken as the end point in this test $[21,22]$.

\subsection{Maximal electroshock seizure test}

Half an hour after i.p. injection of the test compound (100 $\mathrm{mg} / \mathrm{kg}$ ), electroconvulsions were produced, by a current (fixed current intensity of $25 \mathrm{~mA}, 0.2 \mathrm{~s}$ stimulus duration) delivered via ear-clip electrodes by a Rodent Shocker generator (constant-current stimulator Type 221, Hugo Sachs Elektronik, Freiburg, Germany). Six mice were used in the control group and in the experimental groups. The criterion for the occurrence of seizure activity was the tonic hind limb extension (i.e., the hind limbs of animals outstretched $120^{\circ} \mathrm{C}$ to the plane of the body axis) [23].

\subsection{Neurotoxicity screen}

The neurotoxicity of the animals was evaluated by adopting rotarod test [24]. In this test, the animals were trained to maintain equilibrium on a rotating $1 \mathrm{in}$. diameter knurled plastic rod (rotarod, UGO Basile, 47600, Varese, Italy) at a speed of $10 \mathrm{rpm}$ for 60 seconds (sec) in each of three trials.
Only animals that fulfill this criterion were included into the experiment. The animals in the experimental groups $(n=6)$ were given an i.p. injection of one of the test compounds (100 $\mathrm{mg} / \mathrm{kg}$ in $7 \%$ aqueous suspension of tween-80). Thirty minutes later, the mice were placed again on the rotating rod and the motor performance time was recorded up to $60 \mathrm{sec}$. The neurotoxicity was indicated by the inability of the animal to maintain equilibrium on the rod for at least $60 \mathrm{sec}$.

\subsubsection{Immunomodulatory activity}

\subsection{Detection of humoral and cellular immune responses}

Compounds were suspended in $1 \%$ tween-80 aqueous solutions. Mice were divided into seven groups (5mice/group). The $1^{\text {st }}, 2^{\text {nd }}, 3^{\text {rd }}, 4^{\text {th }}$ and $5^{\text {th }}$ groups were injected with a single dose $(100 \mathrm{mg} / \mathrm{kg})$ of the test compounds $\mathbf{5 a}, \mathbf{5 b}, \mathbf{5 c}, \mathbf{5 d}$, and $\mathbf{5 e}$, respectively. Meanwhile, the $6^{\text {th }}$ group received the vehicle $(1 \%$ tween-80 in aqueous solution) and served as vehicle group. The $7^{\text {th }}$ group was injected with phosphate buffer saline (PBS) and was used as normal for the cellular immune response detection from MLN and liver histopathological examination.

Blood samples were collected at intervals, 0 and 30 minutes, 2 hours, 1 day, 1, 2, 3 and 4 weeks post injection from individual mice. The sera were separated by centrifugation at $14,000 \mathrm{~g}$ at $4{ }^{\circ} \mathrm{C}$ for $20 \mathrm{~min}$, and then frozen at $-20^{\circ} \mathrm{C}$ till being used.

\subsection{Detection of IgM and IgG levels using enzyme linked immunosorbent assay (ELISA)}

The IgM and IgG sera levels in different experimental groups were detected by ELISA according to Maghraby and Bahgat (2004) [25] on plates coated with $50 \mu \mathrm{L} /$ well sera (1:100). After coating, plates were incubated overnight at $4{ }^{\circ} \mathrm{C}$, washed three times with PBS containing $0.05 \%$ Tween- 20 (PBS-T). Plates were blocked against non-specific binding using $100 \mu \mathrm{l} /$ well of blocking buffer [PBS-T in $5 \%$ fetal calf serum (FCS)] and incubated at $37^{\circ} \mathrm{C}$ for $2 \mathrm{~h}$. After three washes with PBS-T, peroxidase conjugated anti-mouse IgM and IgG were added $50 \mu \mathrm{L} /$ well at dilution (1:500 for IgG and 1:1000 for IgM) in (PBS-T-FCS) to detect total IgM and IgG levels. Then the plates were incubated at $37{ }^{\circ} \mathrm{C}$ for $1 \mathrm{hr}$ followed by 3 washes with PBS-T. A volume of $50 \mu \mathrm{L} /$ well of $o$-phenylenediamine (OPD) substrate diluted in substrate buffer was used and the plates were left for $10 \mathrm{~min}$ at room temperature till color development. The enzymatic reaction was stopped using $20 \mu \mathrm{L}$ of $2 \mathrm{M}$ sulphuric acid and the changes in optical density (OD) were recorded at $\lambda$ max $490 \mathrm{~nm}$ using a multi-well plate reader (Tecan; Sunrise, Austria, GmbH).

\subsection{Counting the total mesenteric lymph nodes lymphocytes}

Animals were sacrificed at four weeks post-injection; mesenteric lymph nodes (MLNs) were excised, gently teased in Petri dishes containing PBS-T-FCS using glass slides. Cells were washed three times with PBS-T-FCS by centrifugation at $1500 \mathrm{~g}$ at $4{ }^{\circ} \mathrm{C}$ for $10 \mathrm{~min}$. An estimate of cell number in MLN was obtained using haemocytometer. An aliquot cell suspension was diluted $1: 1$ in $4 \%$ trypan blue. The total number of lymphocytes was determined using light microscope (Zeiss Axioskop, Jena, Germany) [26].

\subsection{Histopathological examination}

Slides with the dry paraffin liver sections from each individual mouse were immersed in $2 \times 5 \mathrm{~min}$ baths of xylol at room temperature. Xylol was removed by $2 \times 5$ min baths of $79 \%$ ethanol, rinsed in tap water and stained by the routine 
method [26]. The slides were dipped in haematoxylin for 10-15 min, washed for $5 \mathrm{~min}$ in tap water to eliminate the excess of haematoxylin and cleaned with filter paper around the section, then counter stained with eosin for 5-10 min, rinsed in tap water and dehydrated in $2 \times 2$ min baths of $79 \%$ ethanol. The slides were cleared in $2 \times 2$ min baths of xylol which is miscible with both alcohol and mounting agent. The stained sections were mounted with Canada balsam and examined under the light microscope at fixed magnification.

\subsection{Statistical analysis}

Results were expressed as means \pm standard error of the mean (s.e.m). Statistical analysis of the obtained data was performed using one-way analysis of variance (ANOVA) followed by a Student-Newman-Keuls post hoc comparison. A result was considered statistically significant where $\mathrm{p}<0.05$.

\section{Results and discussion}

\subsection{Chemistry}

Scheme 1 was followed in order to synthesize the target compounds 5a-e and their intermediates 3a-e and 4a-e. The synthesis of 2-amino-1,3,4-thiadiazole intermediates (3a-e) is a one pot two-step reaction. The first step involves the condensation of carboxylic acids (1a-e) with the basic $\mathrm{NH}_{2}$ of thiosemicarbazide (2) in the presence of a coupling reagent to afford the thiocarboxamide acylhydrazide (RCONHNHCSNH 2 ). In the second step the heterocycle is formed by intramolecular cyclodehydration. Several conditions of cyclodehydration have been reported [27], for instance, heating in solvents such as pyridine, DMF, or in the presence of additives such as 1-ethyl-3(3-dimethylaminopropyl)carbodiimide (EDC), while $\mathrm{SOCl}_{2}$, $\mathrm{P}_{2} \mathrm{O}_{5}, \mathrm{H}_{2} \mathrm{SO}_{4}, \mathrm{POCl}_{3}$, Burgess reagent, triphenylphospine, and triflic anhydride are used for the cyclization. In the present work, $\mathrm{POCl}_{3}$ acted as solvent and as coupling, and cyclodehydrating agent for the synthesis of aminothiadiazoles 3a-e. Removal of $\mathrm{POCl}_{3}$ by addition of water (very carefully and slowly) without cooling was crucial step in order to obtain filterable powder after basification with $\mathrm{KOH}$.

Achievement of target compounds 5a-e from 2-amino-5aryl-1,3,4-thiadiazoles (3a-e) could be reached via different pathways such as conversion of amines 3a-e to urea, by Wöhler synthesis, or to carbamates. Then the urea or carbamate is reacted with hydrazine hydrate to afford the target products 5a-e. In the present study, converting 3a-e to urea was tried but annoying troubles have been faced due to the very low solubility of compounds 3a-e even in acetic acid with heating. Thus we preferred to shift towards the carbamate synthesis.

Carbamates have been accomplished by several methods including carbonization of amines or imines by chloroformate, $[28,29]$ or oximinoacetoacetate [30], organic acids in the presence of azides [31,32], organic carbonate under solventfree conditions [33,34] and/or metal-mediated reductive acylation of nitriles [35] or oxime carbonates [36]. In the present work, reaction of the appropriate amine with ethyl chloroformate in different solvents (chloroform, THF, and DMF) at room temperature and higher temperatures in presence of amine (triethylamine) was tried but the low solubility of compounds 3a-e prevented the reactions from going forward. Finally, it has been decided to use the powerful solvent and base pyridine as reaction medium where all amines 3a-e were soluble at room temperature or with slight warming. Stopping the reaction by pouring on aqueous $\mathrm{HCl}$ solution afforded the target carbamates 4 a-e in good yields. The faced troubles during the reaction of amines 3a-e with cyanate (for urea synthesis) or chloroformate (for carbamate synthesis) could also be retrieved to the weak basic properties of $2-\mathrm{NH}_{2}$ as a result of the negative mesomeric and/or inductive effect of the 1,3,4-thiadiazole ring.
Hydrazinecarboxamides 5a-e were obtained by refluxing carbamates 4a-e with hydrazine hydrate. The structure of the final compounds 5a-e was confirmed by spectral (FT-IR, ${ }^{1} \mathrm{H}$ NMR and MS) analyses. In the IR spectra bands at 3370-3450 and $3070-3170 \mathrm{~cm}^{-1}$ have been observed for $\mathrm{NH}_{2}$ and amidic $\mathrm{NH}$ while imine and carbonyl bands have been seen at 1600 1640 and $1510-1520 \mathrm{~cm}^{-1}$, respectively. In the ${ }^{1} \mathrm{H} \mathrm{NMR}$, the aromatic protons have been observed at 7.0-8.0 ppm but the analyses were performed in DMSO- $d_{6} /$ Methanol- $d_{4}$ thus the exchangeable amidic $\mathrm{NH}$ were absent except of 5a. For ${ }^{13} \mathrm{C}$ NMR, all carbons have been assigned particularly the carbonyl and imine carbons at 150-160 and 160-170 ppm, respectively.

\subsection{Biology}

\subsubsection{Anticonvulsant}

The use of predictable animal models is essential for the discovery of new bioactive chemical candidates for the treatment of epilepsy. The antiepileptic drugs (AEDs) discovery programs, allotted three in-vivo animal models including subcutaneous pentylenetetrazole (scPTZ), maximal electroshock seizures (MES), and the kindling model. From these animal models, the scPTZ and MES seizure models, are extensively used are the search for novel AEDs as they are considered as the "gold standards" in the early stages of testing [37]. Interestingly, these two test systems have been claimed to detect new bioactive chemical entities affording protection to generalized absence ("petit mal") seizures and generalized tonic-clonic ("grand mal") seizures, respectively [22].

The initial anticonvulsant activity (Phase 1 screening) of newly synthesized compounds were evaluated according to the protocol given by the epilepsy section of National Institute of Neurological Disorders and Stroke (NINIDS) using the standard protocol adopted by the Antiepileptic Drug Development (ADD) program [38]. Those include the subcutaneous pentylene tetrazole (scPTZ) screen, which is used to identify compounds that elevate seizure threshold, and maximal electroshock seizure (MES) screen, which is indicative of the ability of the test compounds to prevent seizure spread.

The obtained data, expressed as \% protection for the anticonvulsant activity of the test compounds $\mathbf{5 a - e}$ as well as their neurotoxicity are presented in Table 1 and 2 .

The initial anticonvulsant evaluation indicated that all the tested compounds were effective in i.p. MES and scPTZ screens. In the MES test, all of the new entities showed protection in 83 and $100 \%$ at the tested dose level of $100 \mathrm{mg} / \mathrm{kg}$ after $0.5 \mathrm{hr}$ from compound administration, indicating their ability to protect mice from seizure spread. Compounds $\mathbf{5 b}$ and $\mathbf{5 e}$ are the most potent congeners as they exhibited $100 \%$ protection against maximal electric shock at dose level of $100 \mathrm{mg} / \mathrm{kg}$. Moreover, compounds $\mathbf{5 a}, \mathbf{5 c}$ and $\mathbf{5 d}$, at the same dose level exerted equipotent activity of $83 \%$ protection. Meanwhile diphenyl hydantoin, used as reference drug, exhibit $100 \%$ protection at dose level of $40 \mathrm{mg} / \mathrm{kg}$.

Concerning the scPTZ screen, compound 5 e $(100 \mathrm{mg} / \mathrm{kg})$ was found to be the most potent as it exhibited $100 \%$ protection against scPTZ-induced seizures in mice. Meanwhile, the reference drug exhibited $100 \%$ protection at dose level of $40 \mathrm{mg} / \mathrm{kg}$. On the other hand, compound $\mathbf{5 a}, \mathbf{5 b}, \mathbf{5 c}$ and $\mathbf{5 d}$ exhibited equipotent activity of $50 \%$ protection at the tested dose level $(100 \mathrm{mg} / \mathrm{kg})$.

Regarding the neurotoxicity, acute toxicity from antiepileptic drugs in rodents almost invariable is manifested by neurological deficits. These include sedation, altered motor activity, ataxia, and impaired righting reflexes. These effects of antiepileptic drugs are often summarized by tern "neurotoxicity". Minimal neurological deficit, such as impaired motor function, can be detected by standardized test (rotarod test) [24]. 
Table 1. Anticonvulsant activity of compounds 5a-e against pentylenetetrazole and electro-induced seizures in mice.

\begin{tabular}{|c|c|c|c|}
\hline \multirow[t]{2}{*}{ Compound number } & \multirow[t]{2}{*}{ Dose, mmol/kg (mg/kg) } & \multicolumn{2}{|c|}{ Anticonvulsant activity (\% protection) } \\
\hline & & MES a & Sc PTZ b \\
\hline Control & 0 & 0 & 0 \\
\hline Diphenyl hydantoin & $0.159(40)$ & 100 & 100 \\
\hline $5 \mathrm{a}$ & $0.425(100)$ & 83.3 & 50 \\
\hline $5 b$ & $0.318(100)$ & 100 & 50 \\
\hline $5 c$ & $0.400(100)$ & 83.3 & 50 \\
\hline $5 d$ & $0.377(100)$ & 83.3 & 50 \\
\hline $5 e$ & $0.318(100)$ & 100 & 100 \\
\hline
\end{tabular}

a Data show the percentage protection of MES-induced seizures in mice. Animals ( $\mathrm{n}=6)$ were injection i.p. with the test compound (100 mg/kg). $30 \mathrm{~min}$ latter the mice were subjected to electroconvulsions by a current (fixed current intensity of $25 \mathrm{~mA}, 0.2 \mathrm{~s}$ stimulus duration) delivered via ear-clip electrodes by a Rodent Shocker generator.

b Data show the percentage protection of scPTZ-induced seizures in mice. Animals $(\mathrm{n}=6)$ were sc. injected with PTZ $(85 \mathrm{mg} / \mathrm{kg}), 30 \mathrm{~min}$ after intraperitoneal injection of the test compounds. The mice were observed during the $30 \mathrm{~min}$ post injection of scPTZ for the occurrence of seizures.

Table 2. Neurotoxicity screen of compounds 5a-e by adopting rotarod test.

\begin{tabular}{llll}
\hline Compound number & Dose $\mathbf{~ m o l} / \mathbf{k g} \mathbf{~ ( m g / k g )}$ & Number of animals falling the rotating rod & \% of animals devoided of neurotoxicity \\
\hline $5 \mathrm{a}$ & $0.425(100)$ & $4 / 6$ & 33.3 \\
$5 \mathrm{~b}$ & $0.318(100)$ & $0 / 6$ & 100 \\
$5 \mathrm{c}$ & $0.400(100)$ & $0 / 6$ & 100 \\
$5 \mathrm{~d}$ & $0.377(100)$ & $2 / 6$ & 66.7 \\
$5 \mathrm{e}$ & $0.318(100)$ & $0 / 6$ & 100 \\
\hline
\end{tabular}

The results of the neurotoxicity screening test (Table 2) revealed that, compounds $\mathbf{5 b}, \mathbf{5 c}$ and $\mathbf{5 e}$ were devoid from neurotoxicity, meanwhile compounds $\mathbf{5 a}$ and $\mathbf{5 d}$ exhibited moderate neurotoxicity at a dose of $100 \mathrm{mg} / \mathrm{kg}$.

From the present results we can deduce that compound $\mathbf{5 e}$ was the most potent congener as it showed $100 \%$ protection against both MES as well as scPTZ-induced seizures and was devoid of neurotoxicity Meanwhile, compound $\mathbf{5 b}$ demonstrated $100 \%$ protection against MES-induced seizures only and did not exhibit any neurotoxic effect.

Groups of animals $(n=6)$ were examined 30 min after i.p administration of one of the tested compounds 5a-e (100 $\mathrm{mg} / \mathrm{kg}$ ). Thirty minutes later mice were placed on the rotating rod and the motor performance time was recorded up to 60 sec.

\subsubsection{Humoral immune responses}

\subsubsection{Detection of IgM levels in sera from mice injected with compounds $5 a-e$}

Sera IgM levels at 30 minutes post injection of compounds 5a and 5d or vehicle exhibited significant increase compared with normal, compound $\mathbf{5 b}, \mathbf{5 c}$ or $\mathbf{5 e}$, respectively. On the other hand, IgM levels in sera of mice injected with compounds $\mathbf{5 b}$, 5c and 5e showed no significant change compared to the normal IgM level. Moreover, compounds 5a and 5d exerted increase in IgM levels by 1.16 and 1.14 -folds compared to the vehicle level, respectively (Figure 4). At 2 hours post injection, sera IgM level of compound $\mathbf{5 a}$ and $\mathbf{5 d}$ or vehicle demonstrated significantly higher value than the normal one or that of sera IgM of mice injected with compound $\mathbf{5 b}, \mathbf{5 c}$ or $\mathbf{5 e}$. The IgM levels in sera from mice injected with compound $\mathbf{5 b}, \mathbf{5 c}$ or $\mathbf{5 e}$ were significantly lower than the vehicle level and showed no significant difference from the normal level. In addition, compounds $\mathbf{5 a}$ and $\mathbf{5 d}$ demonstrated 1.25 and 1.22-folds increase in IgM level compared to vehicle IgM serum level, respectively.

Sera from mice injected with compound $\mathbf{5 a}$ or $\mathbf{5 d}$ for 1 day showed 1.52 and 1.46-folds increase in IgM level compared to the normal value, respectively. Similarly, the IgM level of compound $\mathbf{5 a}$ or $\mathbf{5 d}$ showed 1.15 and 1.11-folds increase compared to vehicle IgM serum level. Compounds $\mathbf{5 b}, \mathbf{5 c}$ and 5e exhibited 0.69, 0.56 and 0.67-folds compared to the vehicle.

At 1 week post injection of compound $\mathbf{5 a}$ or $\mathbf{5 d}$, the IgM levels were significantly higher compared to the normal values, compound $\mathbf{5 b}, \mathbf{5 c}$ or $\mathbf{5 e}$ IgM sera level. Moreover, the mice injected with compound $\mathbf{5 b} \mathbf{b} \mathbf{5}$ or $\mathbf{5 e}$, their IgM levels showed
0.63, 0.67 and 0.8 -folds compared to the vehicle levels, respectively. Interestingly, sera IgM levels of mice injected with compound $\mathbf{5 a}$ was significantly higher than that of mice injected with the vehicle. IgM sera levels of mice injected with compound $\mathbf{5 d}$ demonstrated 1.27 -folds increase compared to that of vehicle.

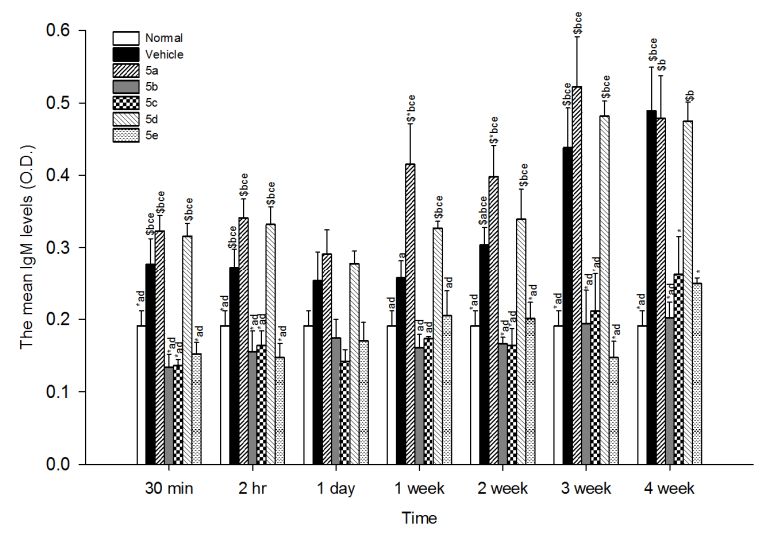

Figure 4. Determination of the IgM level in sera from normal, vehicle, mice injected with single dose $(100 \mathrm{mg} / \mathrm{kg})$ of test compounds $\mathbf{5 a}, \mathbf{5 b}, \mathbf{5 c}, \mathbf{5 d}$ and 5e. IgM normal levels were detected at zero-time before the injection of the test compounds or the Vehicle. Blood samples were collected at intervals, 30 minutes, 2 hours, 1 day, 1, 2, 3 and 4 weeks post injection from individual mice for the determination of IgM sera level. Data presented as mean \pm SEM ( $=5$ ). $\$$ Significantly different from normal group at $\mathrm{p}<0.05$. $*$ Significantly different from vehicle at $\mathrm{p}<0.05$, a significantly different from compound $\mathbf{5 a}$ at $\mathrm{p}<0.05$, b significantly different from compound $\mathbf{5 b}$ at $\mathrm{p}<0.05$, c significantly different from compound $\mathbf{5 c}$ at $\mathrm{p}<0.05$, d significantly different from compound $\mathbf{5 d}$ at $\mathrm{p}<0.05$, e significantly different from compound $\mathbf{5 e}$ at $\mathrm{p}<0.05$.

At 2 weeks, the IgM response in the mice sera injected with compound $\mathbf{5 a}$ and $\mathbf{5 d}$ or the vehicle was significantly higher than the normal values, as well as from mice injected with compound 5b, 5c or $\mathbf{5 e}$. Additionally, IgM sera levels of compound $\mathbf{5 b}, \mathbf{5 c}$ or $\mathbf{5 e}$ were $0.55,0.54$, and 0.66 -folds, respectively compared to the normal level. Also, sera IgM level of mice injected with compound 5a was significantly higher than that of vehicle, while the sera of mice injected with compound 5d demonstrated 1.12-fold increase compared to the vehicle IgM sera levels.

The IgM level in the sera collected from mice three weeks post injection of compound $\mathbf{5 a}$ and $\mathbf{5 d}$ or vehicle showed a 
significant increase when compared with the IgM levels in sera from normal, compound $\mathbf{5 b}, \mathbf{5 c}$ or $\mathbf{5 e}$ at the same time point. Moreover, mice injected with compound $\mathbf{5 b}, \mathbf{5 c}$ or $\mathbf{5 e}$ showed no significant changes compared to the normal IgM level. Moreover, mice injected with compound 5a showed 1.19-fold increase in IgM level as compared with the vehicle (Figure 4).

Four weeks post injection of the compounds $\mathbf{5 a}$ and $\mathbf{5 d}$ or the vehicle, the response of the IgM levels was significantly higher than that of the normal values. Interestingly, the sera IgM levels of compounds $\mathbf{5 a}$ and $\mathbf{5 d}$ demonstrated significantly higher IgM sera levels than mice injected with compound $\mathbf{5 b}$. Moreover, compound $\mathbf{5 b}, \mathbf{5 c}$ or $\mathbf{5 e}$ showed significant decrease compared to the vehicle IgM level.

\subsubsection{Detection of IgG levels in sera from mice injected with compounds $5 a-e$}

At 30 minutes post injection of compound $\mathbf{5 a}$ and $\mathbf{5 d}$ or the vehicle, the levels of IgG in sera showed significant increase compared with the normal level or from mice injected with compound 5b, 5c or 5e. Moreover, mice injected with compound $\mathbf{5 b}, \mathbf{5 c}$ or $\mathbf{5 e}$ showed no significant change compared to the normal IgG level. In addition, both mice injected with compound 5a and $\mathbf{5 d}$ showed 1.14 and 1.22 -folds increase in the IgG level compared to vehicle (Figure 5).

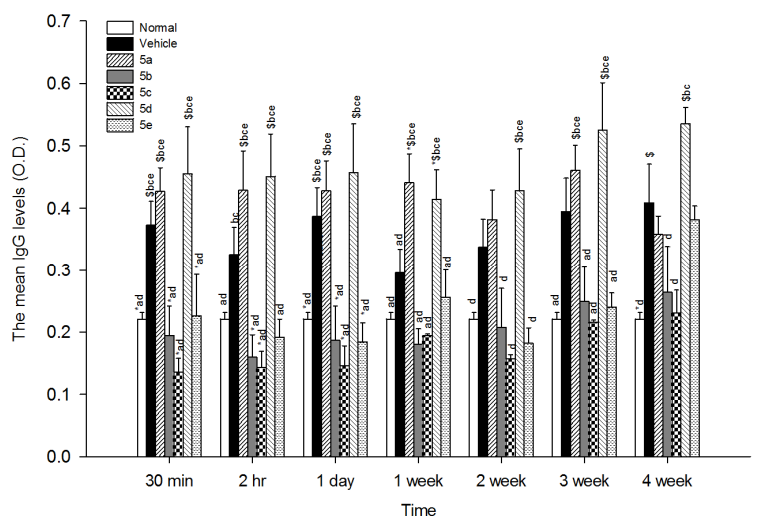

Figure 5. Determination of the IgG level in sera of normal, vehicle and mice injected with single dose $(100 \mathrm{mg} / \mathrm{kg})$ of test compounds $\mathbf{5 a}, \mathbf{5 b}, \mathbf{5 c}, \mathbf{5 d}$ and 5e. IgG normal levels were detected at zero-time before the injection of the test compounds or the Vehicle. Blood samples were collected at intervals, 30 minutes, 2 hours, 1 day, 1, 2, 3 and 4 weeks post injection from individual mice for the determination of IgG sera level. Data presented as mean \pm SEM $(n=5)$. \$ Significantly different from normal group at $p<0.05$ * Significantly different from vehicle at $\mathrm{p}<0.05$, a significantly different from compound $\mathbf{5 a}$ at $\mathrm{p}<0.05$, b significantly different from compound $\mathbf{5 b}$ at $\mathrm{p}<0.05$, c significantly different from compound $\mathbf{5 c}$ at $\mathrm{p}<0.05$, d significantly different from compound $\mathbf{5 d}$ at $\mathrm{p}<0.05$, e significantly different from compound $\mathbf{5 e}$ at $\mathrm{p}<0.05$.

The IgG level in the sera collected at 2 hours post injection of mice with compound $\mathbf{5 a}$ or $\mathbf{5 d}$ were significantly higher than the normal, compound $\mathbf{5 b}, \mathbf{5 c}$ or $\mathbf{5 e}$ IgG level. Vehicle showed significant increase in sera IgG levels compared to the IgG level in the sera from compound $\mathbf{5 b}$ or $\mathbf{5 c}$. On the other hand, compounds 5a and $\mathbf{5 d}$ demonstrated 1.32 and 1.38-folds increase in IgG levels compared to the vehicle level, respectively (Figure 5).

At 1 day post injection, the IgG levels in the sera of the mice injected with compounds $\mathbf{5 a}$ and $\mathbf{5 d}$, demonstrated a significant increase compared to the normal values or compounds $\mathbf{5 b}, \mathbf{5 c}$ and 5e. Vehicle showed significant increase in serum IgG levels compared to normal levels from un-treated mice and those injected with compounds $\mathbf{5 b}, \mathbf{5 c}$ or $\mathbf{5 e}$. Furthermore, compound 5a and 5d showed 1.1-fold and 1.18-folds increase in IgG level compared to the vehicle IgG level, respectively (Figure 5).
At one week, the IgG level in mice sera injected with compounds $\mathbf{5 a}$ and $\mathbf{5 d}$ was significantly higher than that of the normal, vehicle, compounds $\mathbf{5 b}, \mathbf{5 c}$, and $\mathbf{5 e}$ (Figure 5).

At two weeks post injection, the IgG serum level of mice injected with compound $\mathbf{5 d}$ was found to be significantly higher than the normal or compounds $\mathbf{5 b}, \mathbf{5 c}$ or $\mathbf{5 e}$. There was no significant difference between the remaining groups. However, compound 5d demonstrated 1.27-fold increase in IgG level as compared to the vehicle level (Figure 5).

At three weeks, the IgG levels in mice sera injected with compound $\mathbf{5 a}$ or $\mathbf{5 d}$ was significantly higher than the normal, compounds 5b, 5c and 5e levels. Moreover, the IgG levels in sera of mice injected with compounds $\mathbf{5 a}$ and $\mathbf{5 d}$ demonstrated 1.17 and 1.33- folds increase compared to vehicle, respectively (Figure 5). There is no significant difference between the IgG level of the vehicle and normal group.

At four weeks post injection, the IgG levels of mice sera of vehicle or compound 5d, were significantly higher than the normal level. Moreover, the sera of mice injected with compound 5d demonstrated significantly higher IgG levels compared to sera from mice injected with compound $\mathbf{5 b}$ or $\mathbf{5 c}$. There were no statistical changes in the IgG levels between the vehicle group and any of the tested groups (Figure 5).

\subsubsection{Cellular immune responses}

Data of the cellular immune responses revealed that the mean of the total number of MLN cells from mice injected with 5a (114.9 \pm 37$), \quad 5 b \quad(128.5 \pm 13.8), \quad 5 c \quad(121.5 \pm 54.4), \quad 5 d$ (95.6 \pm 29.3$)$, and $5 e(124 \pm 24.4)$ showed insignificant increase $(1.30,1.45,1.38,1.08$ and 1.41-folds, respectively) as compared with total number of normal MLN cells $(88.1 \pm 18)$ (Figure 6). There was an insignificant decrease in the mean of total number of MLN cells of the vehicle $(66.6 \pm 18.6)$ as compared with that of the normal or mice injected with compounds $\mathbf{5 d}$, 5a, $5 \mathbf{c}$ or $5 \mathbf{e}(0.76,0.7,0.58,0.55$ and 0.54 , folds, respectively). Meanwhile, there was a 1.92 -fold increase in mean total number of MLN cells of mice injected with compound $\mathbf{5 b}$ or the vehicle. On the other hand, no significant change in the mean of total number of MLN cells was detected in between different tested groups (Figure 6).

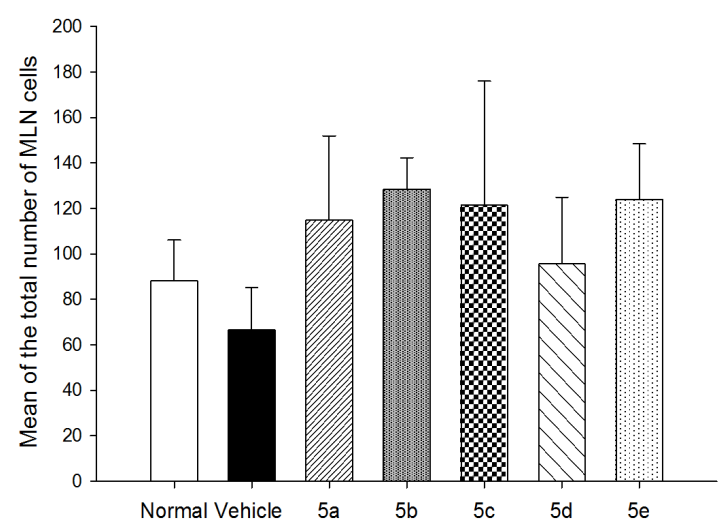

Figure 6. Determination of the total mean number of mesenteric lymph nodes lymphocytes of normal, vehicle and mice injected with single dose $(100 \mathrm{mg} / \mathrm{kg})$ of test compounds $\mathbf{5 a}, \mathbf{5 b}, \mathbf{5 c}, \mathbf{5 d}$ and $\mathbf{5 e}$.

Conclusively, our humoral immunological study showed that compound $\mathbf{5 a}$ and $\mathbf{5 d}$ had immunostimulatory responses. Interestingly, compound $\mathbf{5 a}$ expressed a higher immunestimulatory response than that of the vehicle. On the other hand, compound $\mathbf{5 b}, \mathbf{5 c}$, or $\mathbf{5 e}$ had an immunosuppressive response than the vehicle. 
Table 3. The mean of the total number of lymphocyte infiltrations and lymphocyte aggregations in the liver sections of mice injected with compounds 5a-e.

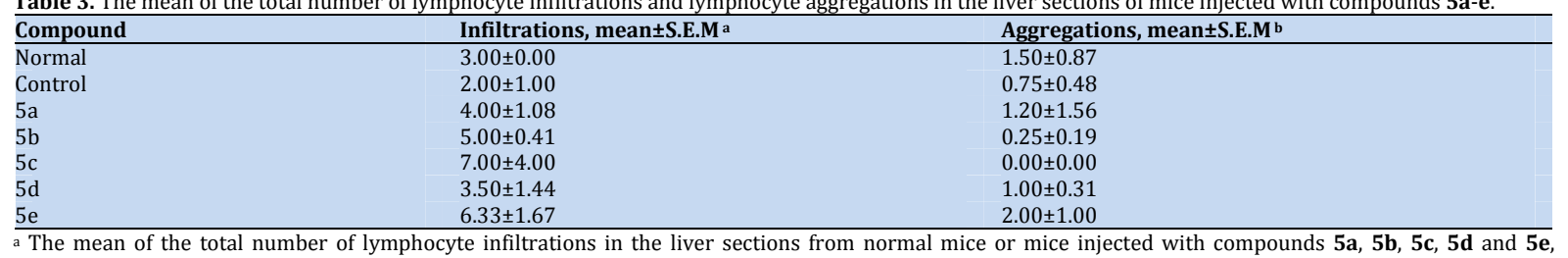

a The mean of the total number of lymphocyte infiltrations in the liver sections from normal mice or mice injected with compounds $\mathbf{5 a}$, $\mathbf{5 b}$, $\mathbf{5 c}$, $\mathbf{5 d}$ and $\mathbf{5 e}$, respectively.

b The mean of the total number of lymphocyte aggregations in the liver sections from normal mice or mice injected with compounds $\mathbf{5 a}$, $\mathbf{5 b}$, $\mathbf{5 c}$, $\mathbf{5} \mathbf{d}$ and $\mathbf{5 e}$, respectively.

Moreover, mice injected with compound $\mathbf{5 a}, \mathbf{5 b}, \mathbf{5 c}, \mathbf{5 d}$ or 5e showed an increase in the mean of the total number of MLN cells as compared with total number of native MLN cells. There was no significant change in the mean of total number of MLN cells from each compound as compared with the other one.

\subsubsection{Microscopic examination of liver sections}

Liver sections from mice injected with compounds $\mathbf{5 a}, \mathbf{5 b}$, $\mathbf{5 c}$ and $\mathbf{5 d}$ showed small lymphocytes infiltration around blood vessels and lymphatic aggregations in hepatic parenchyma, which were the predominant microscopic observations (Figure 7). Liver sections from mice injected with compound 5e showed a large lymphocytes infiltrations as well as lymphocytes aggregations (Table 3). There was no significant change between the numbers of lymphocyte infiltrations or aggregations in the liver sections of vehicle, $\mathbf{5 a}, \mathbf{5 b}, \mathbf{5 c}, \mathbf{5 d}$ or $\mathbf{5 e}$ as compared with normal liver sections (Table 3). Compounds 5a-e showed no hepatocytes degenerations. Our observation was in agreement with Amir et al. [39], whereas the derivatives of 1,2,4-triazolo-[3,4-b]-1,3,4-thiadiazole derivatives of ibuprofen and biphenyl-4-yloxy acetic acid do not show any significant pathological changes.
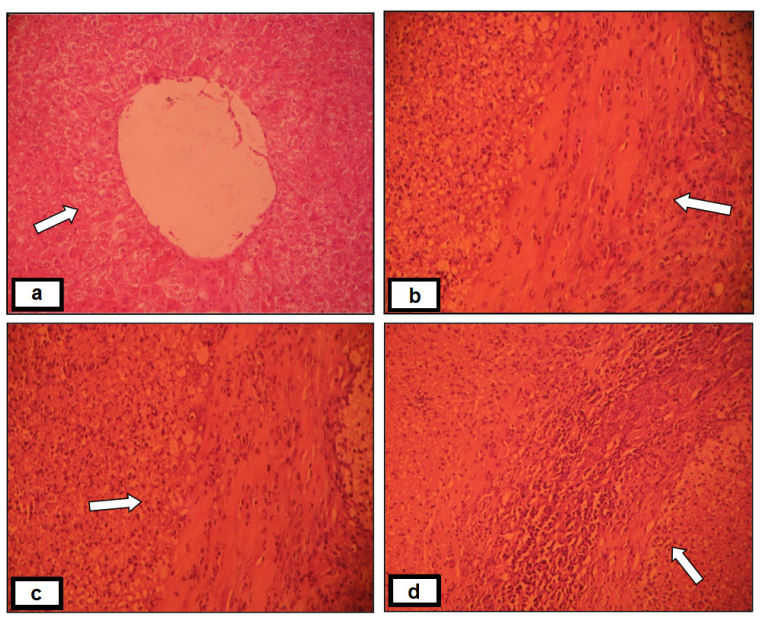

Figure 7. Histopathological appearance of the liver sections from normal or mice injected with compound 5e. Arrows point to normal hepatocytes and no lymphocyte infiltration; control liver [image a] and large lymphocyte infiltrations and lymphocyte aggregations; in liver section from mice injected with compound 5e [images b, c, and d] (Hematoxylin and eosin-stain 200).

\section{Conclusion}

In summary, the well-recognized anticonvulsant activity of thiadiazole and hydrazinecarboxamide pharmacophores has been emphasized and compared with newly synthesized compounds 5a-e. These compounds 5a-e could be used to foster the anticonvulsant activity of other week antiepileptic drugs. On the other hand, new activity as immunomodulators has been discovered for the investigated compounds 5a-e.

\section{Acknowledgements}

The authors would like to thank the National Research Centre, Dokki, Cairo, Egypt for the support and financing of the research through the project No. 10010302.

\section{References}

[1]. Masihi, K. N. Immunotherapy of Infections, $1^{\text {st }}$ edition, New York: Marcel Dekker, 1994.

[2]. Masihi, K. N. Int. J. Immunopharmacol. 1997, 19, 463-617.

[3]. Foroumadi, A.; Jazayeri, S.; Moshafi, M. H.; Firoozpour, L.; Emami, S.; Rajabalian, S.; Haddad, M.; Pahlavanzadeh, F.; Esnaashari, M.; Shafiee, A. Eur. J. Med. Chem. 2009, 44, 1205-1209.

[4]. Goksen, U. S.; Kelekci, N. G.; Goktas, O.; Koysal, Y.; Kilic, E.; Isik, S. Aktay, G.; Ozalp, M. Bioorg. Med. Chem. 2007, 15, 5738-5751.

[5]. Mavrova, A. T.; Wesselinova, D.; Tsenov, Y. A.; Denkova, P. Eur. J. Med Chem. 2009, 44, 63-69.

[6]. Pattanayak, P.; Sharma, R.; Sahoo, P. K. Med. Chem. Res. 2009, 18, 351 361.

[7]. Kus, C.; Kilcigil, G. A.; Ozbey, S.; Kaynak, F. B.; Kaya, M.; Coban, T.; Eke B. C. Bioorg. Med. Chem. 2008, 16, 4294-4303.

[8]. Behrouzi-Fardmoghadam, M.; Poorrajab, F.; Ardestani, S. K.; Emami, S.; Shafieea, A.; Foroumadi, A. Bioorg. Med. Chem. 2008, 16, 45094515 .

[9]. Bhuva, H.; Sahu, D.; Shaha, B.; Modia, D.; Patel, M. Pharmacology Online 2011, 1, 528-543.

[10]. Takezawa, R.; Cheng, H.; Beck, A.; Ishikawa, J.; Launay, P.; Kubota, H.; Kinet, J. P.; Fleig, A.; Yamada, T.; Penner, R. Mol. Pharmacol. 2006, 69, 1413-1420.

[11]. Yoshino, T.; Ishikawa, J.; Ohga, K.; Morokata, T.; Takezawa, R.; Morio, H.; Okada, Y.; Honda, K.; Yamada, T. Eur. J. Pharm. 2007, 560, 225-233.

[12]. Vo, N. H.; Chen, S.; Che, S. US patent US 2007/0254925 A1, 2007.

[13]. Jingwu, D.; Bin, J. WO 2007/073503 A2, 2007.

[14]. Beraldo, H.; Gambinob, D. Mini Rev. Med. Chem. 2004, 4, 31-39.

[15]. Rajak, H. R.; Avantika, A.; Poonam, P.; Singh, T. B.; Ravichandran, V.; Chander, S. P.; Dhar, K. M. Bioorg. Med. Chem. Lett. 2011, 21, 57355738

[16]. Tu, G. G.; Huang, H. H.; Li, G.; Xiong, F.; Mai, X.; Zhu, H. W.; Kuang, B. H.; $\mathrm{Xu}, \mathrm{W}$. H. Bioorg. Med. Chem. 2008, 16, 6663-6668.

[17]. Rango, R. V.; Srinivasan, V. R. Indian J. Chem. 1970, 8, 509-513.

[18]. Pryde, D. C.; Maw, G. N.; Planken, S.; Platts, M. Y.; Sanderson, V.; Corless, M.; Stobie, A.; Barber, C. G.; Russell, R.; Foster, L.; Barker, L.; Wayman, C.; Van der Graaf, P.; Stacey, P.; Morren, D.; Kohl, C.; Beaumount, K.; Coggon, S.; Tute, M. J. Med. Chem. 2006, 49, 44094424.

[19]. Doyle, K. M.; Kurzer, F. Tetrahedron 1976, 32, 2347-2352.

[20]. Fariello, R. G.; McArthur, R. A.; Bonsignori, A.; Cervini, M. A.; Maj, R.; Marrari, P.; Pevarello, P.; Wolf, H. H.; Woodhead, J. W.; White, H. S.; Varasi, M.; Salvati, P.; Post, C. J. Pharm. Exp. Therap. 1998, 285, 397 403.

[21]. Alam, O.; Mullick, P.; Verma, S. P.; Gilani, S. J.; Khan, S. A.; Siddiqui, N.; Ahsan, W. Eur. J. Med. Chem. 2010, 45, 2467-2472.

[22]. Krall, R. L.; Penry, J. K.; White, B. G.; Kupferberg, H. J.; Swinyard, E. A. Epilepsia 1978, 19, 409-428.

[23]. Luszczki, J. J.; Czuczwar, M.; Gawlik, P.; Sawiniec-Pozniak, G.; Czuczwar, K.; Czuczwar, S. J. J. Neural. Transm. 2006, 113, 1157-1168.

[24]. Dunham, N. W.; Miya, T. S. Amer. Pharm. Assoc. 1957, 46, 208-209.

[25]. Maghraby, A.; Bahgat, M. Arzneimittel-Forschung, 2004, 54, 545-550.

[26]. Maghraby, A., M. Sc. Thesis submitted to the faculty of science, Cairo University, Egypt, 1989, p. 43-46.

[27]. Augustine, J. K.; Vairaperumal, V.; Narasimhan, S.; Alagarsamy, P.; Radhakrishnan, A. Tetrahedron 2009, 65, 9989-9996. 
[28]. Yadav, J. S.; Reddy, G. S.; Reddy, M. M.; Meshram, H. M. Tetrahedron Lett. 1998, 39, 3259-3262.

[29]. Balack, D. A.; Arndtsen, B. A. Org. Lett. 2006, 8, 1991-1993.

[30]. Elghamry, I. Synthetic Commun. 2009, 39, 3010-3015.

[31]. Lebel, H.; Leogane, O. Org. Lett. 2006, 8, 5717-5720.

[32]. Lebel, H.; Leogane, O. Org. Lett. 2005, 7, 4107-4110.

[33]. Han, C.; Porco, J. A. Jr. Org. Lett. 2007, 9, 1517-1520.

[34]. Curini, M.; Epifano, F.; Maltese, F.; Rosati, O. Tetrahedron Lett. 2002, 43, 4895-4897.

[35]. Caddick, S.; Judd, D. B.; Lewis, K.; Reich, M. T.; Williams, M. R. V. Tetrahedron 2003, 59, 5417-5423.

[36]. Sun, C.; Weinreb, S. Synthesis 2006, 3585-3588.

[37]. White, H. S. Epilepsia 2003, 44, 2-8.

[38]. Porter, R. J.; Cereghino, J. J.; Gladding, G. D.; Hessie, B. J.; Kupferberg, H. I.; Scoville, B.; White, B. G. Cleveland Clin. Q. 1984, 51, 293-305.

[39]. Amir, M.; Kumar, H.; Javed, S. A. Eur. J. Med. Chem. 2008, 43, 20562066. 